\title{
The MOOC: Challenges and Opportunities from a Pedagogical View
}

\author{
Soumaya El Emrani \\ LIROSA Laboratory \\ Abdelmalek Essaâdi University \\ Tetuan, Morocco
}

\author{
Ali El Merzouqi \\ LIROSA Laboratory \\ Abdelmalek Essaâdi University \\ Tetuan, Morocco
}

\author{
Mohamed Khaldi \\ LIROSA Laboratory \\ Abdelmalek Essaâdi University \\ Tetuan, Morocco
}

\begin{abstract}
For many years, E-Learning with its multiple forms, has begun to be an indispensable tool in the world of access to knowledge. The MOOC (Massive Online Open Course) as a new one of these learning modes has emerged as a new revolution with rich opportunities, especially for university students. Nonetheless, despite its various developments, MOOC has faced several challenges and constraints.

In this article, the authors try to highlight the opportunities as well as challenges that the MOOC has experienced, especially on the pedagogical level, considering its inadequacy in what concerns the needs and preferences of each individual learner. This is why they propose a new approach that can provide a MOOC that is adaptive according to each learner's profile.
\end{abstract}

\section{General Terms}

Education, E-Learning, MOOC, Learner

\section{Keywords}

Adaptative cMOOC, Learning Styles, Learner's profile

\section{INTRODUCTION}

Education is widely considered as an effective instrument for the development of countries through the fight against ignorance and illiteracy, the diffusion of science and knowledge, as well as the improvement of the level of skills and competences in each country or nation, which has made the education system a measure of the progress of peoples and nations.

Today, the world is moving towards a new education system, based on the terms of a new culture dedicated to values, concepts of globalization, openness, partnership, and competition.

Looking back in history, we find that the roots of the notion of distance learning, in its broad sense, appeared more than two centuries ago, beginning with the years of correspondence, dating back to 1728 [1], followed by the period of distance learning via radio (1904), then television (1953) [2], arriving at the emergence of E-Learning. The technical and digital revolutions, add to the development associated with the use of computers and the Internet, were the main cause for the development of this type of learning as a modern revolution in the education system.

Over time, E-Learning has become a key tool for some people. It has given them the opportunity to study without having to go through the monotonous process of classical learning, especially in developing countries.

Indeed, the MOOC (Massive Online Open Course) represents one of the new modes of E-Learning. However, its concept must not be confused with other forms of E-Learning such as the OER (Online Educational Resources), the OCW (Open Course Ware) [3], the COOC (Corporate Online Open Course), the SOOC (Small Online Open Courses) and the SPOC (Small Private Online Courses).

Within the framework of our research, analytical studies of the existing MOOCs have shown the existence of various educational constraints and challenges.

In fact, the first concern that every designer of MOOC must have, is to make the course adequate and adaptive to each learner, according to his learning styles, given that each learner is characterized by certain criteria that can notably help to discover the various effective learning styles and the adequate and compatible learning methods to improve the learning process efficiency and provide a better time and knowledge management [4].

Likewise, the lack of a proper method of learners' profiling can involuntarily lead to the loss of some learners, especially when it has to do with lifelong learning, where learners can be older and accustomed to conventional learning tools.

\section{THE MOOC AS A REVOLUTION}

The term MOOC was coined for the first time in 2008 by David Cormier (University of Prince Edward Island) as a response to a course called "Connectivism and Connective Knowledge" launched in 2005 by George Siemens (Athabasca University) and Stephen Downes (National Research Council of the United States).

Three years later, American universities adopted the term by creating their own platforms, where tens of thousands of learners registered [5] (see Figure 1). 


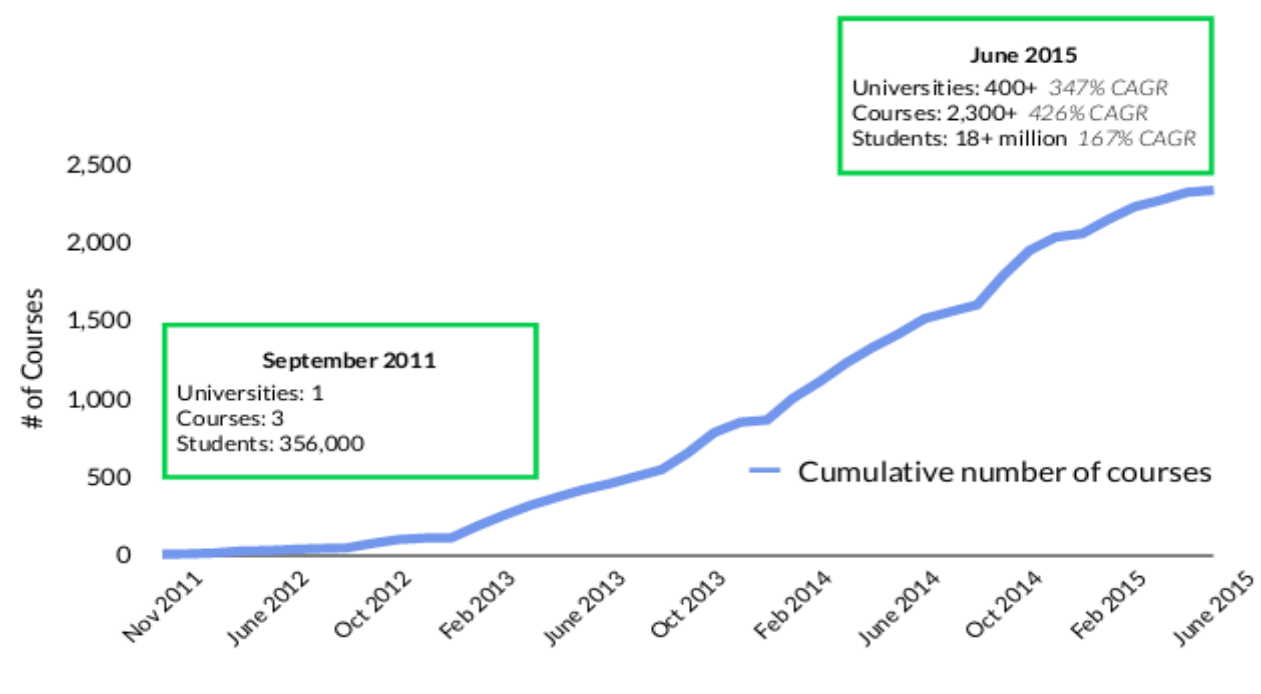

Figure 1: MOOC Courses and students surge, 2011-2015 [6]

A year later, the New York Times announced the year 2012 as "The Year of the MOOC" [7].

On the one hand, MOOC is the acronym for Massive Online Open Course.

- The M (Massive): indicates that the MOOC is addressed to a very large number of registrants, which means that the registration is unlimited, in contrast to the COOC, the SOOC and the SPOC;

- 1st $\mathbf{O}$ (Open): means that the content of the course is available free of charge for everyone and regardless of their level of study. Unfortunately, this is not the case for some platforms!

- 2nd $\mathbf{O}$ (Online): indicates that digital content is available on the internet in real time despite the geographical dispersion of the participants.

- And the $\mathbf{C}$ (Course): means that it is a sharing of knowledge that takes into consideration the pedagogical principles, with a calendar that respects time and date of the start and the end. It is not just a sharing of course materials or videos of university level like the case of the OCW for example.

On the other hand, the MOOC targets a wide learning community differently from the COOC, the SOOC and the
SPOC, and it, therefore, allocates pedagogical accompaniment with assignments, quizzes, and evaluations, which is not the case with other modes of E-Learning such as the OCW and the OER [8].

There are two types of MOOC:

- $x M O O C$ : is based on the transmissive concept approach of classical learning, where the teacher is the sole contributor in the course;

- cMOOC: This MOOC is called "Connectivist". The course here is the fruit of a collaborative work between the teacher and the learners.

This has sparked the emergence of many competing companies, to enhance the experience of E-learning in a revolutionary way, considering it as a potential and a profitable market [9].

Most of the MOOCs provide massive and unlimited courses (150,000 for the first MOOC of Stanford in 2011) [10], offered by elite universities (Harvard, Cambridge, Oxford etc.). Today, these courses are not exclusive to the fields of computing and digital technology (see Figure 2), but they also include various specialties, such as economics, law, literature, human relation, sciences, arts and so on [5].

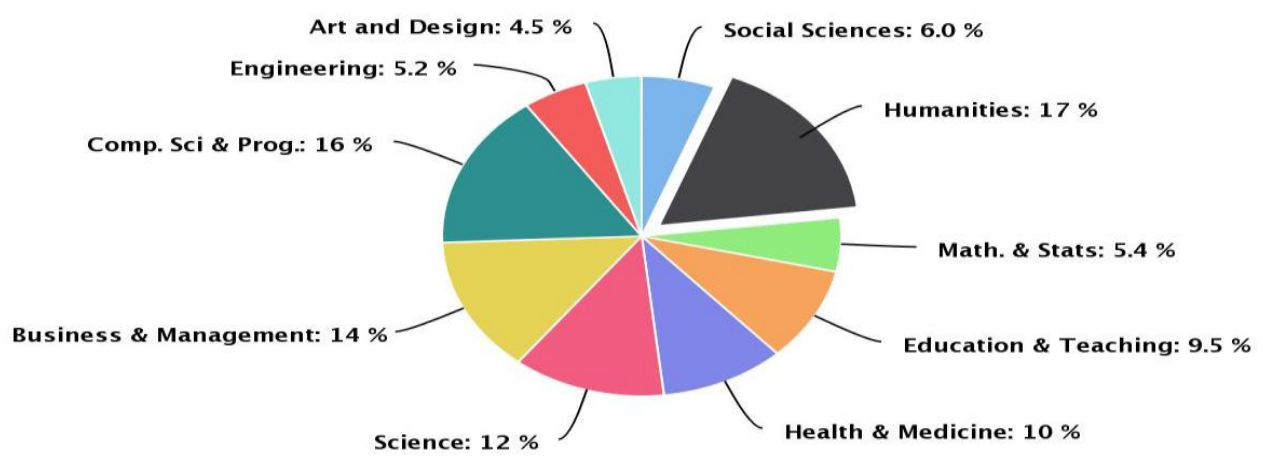

Figure 2: MOOC distribution by subjects in 2014 [11] 


\section{THE MOOC: TOWARD SOME OPPORTUNITIES}

On December 31st, 2014, Internet coverage reached $42 \%$ of the population of our planet, with 3,079,339,857 of users. And since laptop prices are getting cheaper each year, in addition to the emergence of tablets and smart phones, the world has entered "the connected era".

Indeed, universities, academic institutions and companies saw this as a great opportunity to disseminate knowledge and maximize benefits. This sharing could be beneficial to students, professors, universities and the environment alike.

On the one hand, the learner needs only a digital device (Computer, laptop, tablet, or smart phone) and an internet connection. And thanks to the $24 / 7$ availability of the course, MOOC provides to any type of interested learner a selftraining and a free and open scientific reference, without any need to be registered at the MOOC's supplier establishments, and without paying the costs of some training courses that are sometimes expensive [5].

In addition, it allows the student in particular, to consult the same course anytime and anywhere, and to use it in case of absence or delay, or just for revision. The learner can recover the content of the session without leaving one's home and sometimes getting away from one's family etc.

Moreover, the appearance of a MOOC on a CV can show qualities of curiosity, innovation and motivation. According to Claire Romanet (Founder of Elaee), it is considered as a positive point on a $\mathrm{CV}$, which shows that the candidate is aware of the new technologies and is trying to progress professionally. For Jacques Froissant (Responsible of the recruitment agency Altaïde): "When I see a MOOC on a CV, this is a real point of interest on which I will dwell during the job interview" [12].

On the other hand, the professor can always be in contact with a large community of learners participating in the MOOC, without moving to the institution or giving the same course more than once. Providing MOOCs by universities can minimize the problem of massiveness, reduce the costs of equipment, digital devices, internet connection, transportation, electricity, and paper for the printing of course materials, series of exercises, evaluations etc. Consequently, this can directly contribute way to the protection of our planet.

\section{CHALLENGES AND CONSTRAINTS}

Indeed, the universities providing MOOC facilitated and accelerated access to knowledge. Nevertheless, because of their limited resources (time, staff and capital), they use very basic methods; as recording courses in video formats and downloading them on their MOOC and sometimes with files in PDF format etc.

However, the educational problems remain the same. Filming courses exposed in the same classical way is, in fact, only to put online learners in front of the same reality, and in the face of the same pedagogical challenge of conventional learning, where they are obliged to follow the methodology and rhythm imposed by the professor, with limited interaction during the presentation of the course, and with no respect to the adaptation of the course to the different types of learners, to their needs, skills and abilities. This disharmony affects negatively the learner's commitment and performance. For example, the Duke Center for Technology, recorded the variation in the number of visitors to their online platform, for a bioelectricity course, where visualizations decreased week after week (see Figure 3).

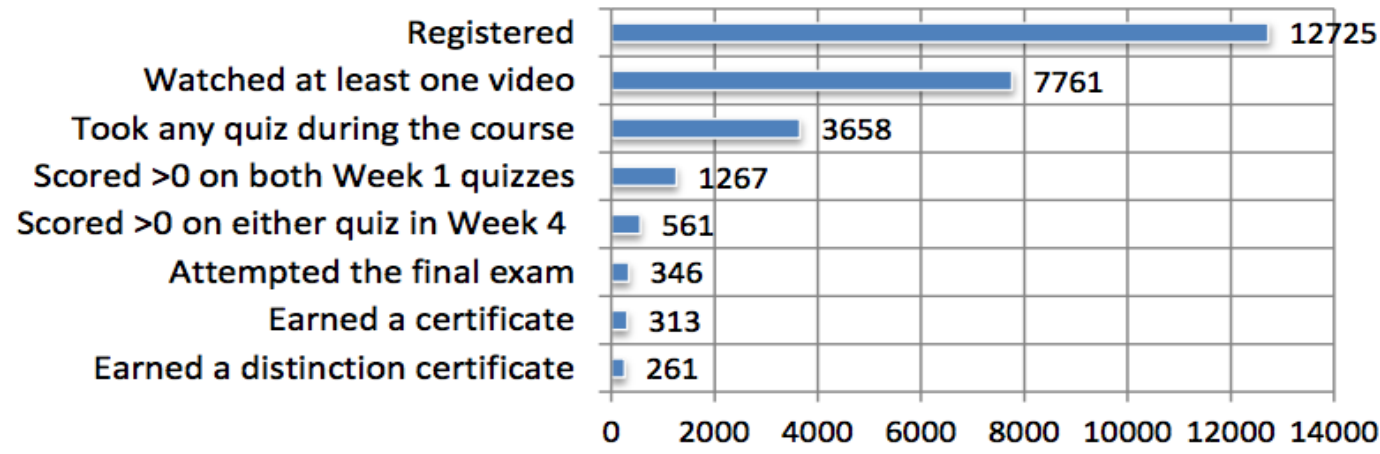

Figure 3: Student Persistence in Bioelectricity, Fall 2012 (Duke University MOOC[13]

As a result, despite the massive rate of enrollments for a course (which can sometimes reach thousands), the number of active participants who follow the course from the beginning to the end is always modest compared to the first rate [14].

\section{OBJECTIVE AND CONTRIBUTION}

Our research aims at optimizing performance by minimizing restrictions and improving the level of learning, in order to have a relevant academic education system adapted to the scientific and technical needs, as well as the environmental, emotional, sociological, physiological and psychological aspects of a 21 st century learner.

The main objective of this thesis project is to conceive a new pedagogical approach based on the adaptation of the courses to the profile of each connected learner; that is to design and produce an adaptive cMOOC.
The model to be developed will allow an effective learning, despite the differences among the types of learners, based on the principles of differentiated pedagogy; which means that the teacher takes into consideration that he is working with learners who have different skills and learning styles, thus approaching the theory of the models of learning styles.

\section{WHAT IS A LEARNING STYLE?}

The specialists discussed the learning styles from different points of view, which gave way to many theories on how learners prefer to learn depending on different definitions of the learning styles [4] [13]. Some of them are focused on the behavior learning characteristics, while others are concentrated on the process inferred from the behavior [4]

According to R. Dunn and K. Dunn (1993) the learning style is the way in which each learner begins to concentrate on, 
treats and retrains new and difficult information [4]. While Honey and Mumford (1992) define the learning style as the attitudes and behaviors that determine the learning preferences for each learner [14].

\section{THE PARTICULARITY OF THE LEARNING STYLE}

Every individual learns and treats information in his or her own way. Learners, however, may sometimes share some learning styles, preferences or approaches.

When a learner uses a learning method suggested by a friend, a teacher, or someone else, and even if it is appropriate for him, one may feel unable to follow the same path or learn in a flexible way because he may have a different learning style, as his approaches and preferences may be different.

\section{THE METHODS USED IN DETERMINING THE CMOOC LEARNING STYLES}

Generally, there are two different ways to determine the learner's learning style in an adaptive system or in an adaptive cMOOC as is the case in this study:

- The first uses standardized questionnaires to identify the learning style for a particular model [15]. On the one hand, the answer to several questions takes much time. On the other hand, this requires good concentration and the determination of the personality of the person himself which evokes his actual needs, not what he wants to do or likes to have.

- The second option aims at the automatic detection of a learning style based on the interaction between the learner and the learning systems [16]. This option does not take much time, and helps to collect the preferences, skills and the actual learner needs, but this requires a reliable and effective system, which can involve the interaction of learners with the corresponding style [17].

Determining the learning styles of a learner in a cMOOC, aims mainly at analyzing the behavior and preferences, to enable the system to identify a particular learning model based on this kind of data for each of the connected learners. The resulting model reflects the current and actual state of the learner with a possibility of automatic updates according to the new attitudes gathered throughout the registration period in a cMOOC.

\section{CONCLUSION}

Eventually, higher education is considered as a key to the development of nations and a fundamental entity of society in general and of the educational system in particular.

The important developments that have accompanied the distance learning system reflect that the constant need for knowledge has clearly contributed to conceive the different methods adapted to the social, economic and cultural conditions that each era has undergone.

Despite high expenditures and costs of university education around the world, digital innovation has introduced MOOC as a new option for students. This opportunity will be more effective with our approach based on the learning styles models.
A next step will be focused on an analytical study of some learning styles models so as to, choose among them the one or the ones which meet best our requirements and on which our conception will be based. This work will be the stepping-stone required to build the learner's profile.

\section{REFERENCES}

[1] B. Holmberg, "The evolution, principles and practices of distance education," Distance Education, 2005. [Online]. Available: http://www.mde.unioldenburg.de/download/asfvolume11_eBook.pdf.

[2] MARCO BERTOLINI, "Petite histoire de la formation à distance - infographie - Formation 3.0." [Online]. Available: https://format30.com/2014/02/04/petitehistoire-de-la-formation-a-distance-infographie/. [Accessed: 16-Feb-2017].

[3] “A_la_decouverte_des_MOOC-2.pdf." [Online]. Available: $\quad \mathrm{http} / / / \mathrm{www}$.france-universitenumerique.fr/IMG/pdf/a_la_decouverte_des_mooc2.pdf. [Accessed: 26-Jun-2015].

[4] R. LeBlanc and J. Chevrier, "Le style d'apprentissage," Educ. Francoph., vol. XXVIII, no. 1, p. 189, 2000.

[5] M. K. S. El Emrani, a. El Merzouqi, "The MOOCs in face of pedagogical constraints," Int. J. Eng. Sci. Innov. Technol., vol. 4, no. 5, pp. 7-13, 2015.

[6] M. Moe, D. Quazzo, N. Franco, M. Cohn, and B. Thompson, 2020 Vision A History of the Future, Advance Ed.

[7] T. R. Liyanagunawardena, P. Parslow, and S. A. Williams, "Dropout: MOOC Participants' Perspective," Proc. Eur. MOOC Stakehold. Summit 2014, pp. 95-100, 2014.

[8] Anne Gibassier, "MOOC et e-learning, quelles différences? | Formation et Nouvelles Technologies." [Online]. Available: http://www.formation-et-nouvellestechnologies.fr/formation-e-learning/mooc-et-e-learningquelles-differences. [Accessed: 16-Feb-2017].

[9] J. Gilliot, X. Lagrange, G. Simon, J. Gilliot, X. Lagrange, G. Simon, M. Briand, J. Gilliot, G. Texier, X. Lagrange, G. Simon, and M. Briand, "Int ' egrer des MOOC dans une formation d' ing ' enieurs To cite this version :," 2015.

[10] C. V. Jean-Sébastien Dubé, Dany Turcotte, "Les MOOC," $2013 . \quad$ [Online]. Available: https://www.usherbrooke.ca/ssf/fileadmin/sites/ssf/Face et_pile/face_pile_MOOC_final.pdf. [Accessed: 26-Jun2015].

[11] Dhawal Shah, "Online Courses Raise Their Game: A Review of MOOC Stats and Trends in 2014 - Class Central," Class Central, 2014. [Online]. Available: https://www.class-central.com/report/moocs-stats-andtrends-2014/. [Accessed: 01-Mar-2017].

[12] Benjamin Dusaussoy, "Mooc: comment en parler sur son CV?" [Online]. Available: https://www.keljob.com/editorial/chercher-unemploi/cv/detail/article/mooc-comment-en-parler-surson-cv.html. [Accessed: 16-Feb-2017].

[13] R. Plonsey and R. C. Barr, "Bioelectricity: A quantitative approach," Bioelectr. A Quant. Approach, pp. 1-528, 2007. 
[14] Y. A. Chakor and N. El Faddouli, "Abandonment of Learners MOOC Problematic Analysis and Proposed Solutions," vol. 153, no. November, pp. 35-37, 2016.

[15] Y. C. Chang, W. Y. Kao, C. P. Chu, and C. H. Chiu, "A learning style classification mechanism for e-learning," Comput. Educ., vol. 53, no. 2, pp. 273-285, 2009.
[16] U. Ocepek, Z. Bosnić, I. Nančovska Šerbec, and J. Rugelj, "Exploring the relation between learning style models and preferred multimedia types," Comput. Educ., vol. 69, pp. 343-355, 2013. 